\title{
A PROPOSTA DE FLEXIBILIZAÇÃO DA LEGISLAÇÃO SOBRE AGROTÓXICOS (PROJETO DE LEI No6.299/2002): ANÁLISE À LUZ DO DIREITO FUNDAMENTAL À SADIA CONDIÇÃO DE VIDA E AO MEIO AMBIENTE EQUILIBRADO
}

\author{
Marília Gurgel Rocha de Paiva e Sales*
}

\section{RESUMO}

Propõe-se a análise de projeto normativo que intenciona facilitar uso de biocidas (Projeto de lei nº.299/2002). A importância do tema emerge das evidências científicas que recomendam cautela no manejo de agrotóxicos, para garantia da vida humana e dos recursos naturais às presentes e futuras gerações. Os objetivos específicos são: delinear o direito fundamental à sadia condição de vida e ao meio ambiente equilibrado; compreender os princípios do desenvolvimento sustentável e da vedação do retrocesso ambiental; e avaliar a proposta de flexibilização normativa sobre agrotóxicos. A metodologia aplicada é aquela do método descritivo-dedutivo, com técnica normativa e bibliográfica de cunho qualitativo.

PALAVRAS-CHAVE: Meio ambiente, sustentabilidade, agrotóxicos, princípios.

\section{THE MORE FLEXIBLE PROPOSAL OF THE LEGISLATION ON PESTICIDES (DRAFT LAW No6,299/2002): ANALYSIS BY THE FUNDAMENTAL RIGHT TO HEALTHY LIVING CONDITIONS AND A BALANCED ENVIRONMENT}

\begin{abstract}
Proposed the analysis of a normative project that intends to facilitate the use of biocides (Bill no. 6,299/2002). The topic's importance emerges from scientific evidence that recommends caution in the management of agrochemicals to guarantee human life and natural resources for present and future generations. The specific objectives are: to outline the fundamental right to healthy living conditions and a balanced environment; to understand the principles of sustainable development and the prohibition of environmental regression; and to evaluate the proposal of normative flexibility on pesticides. Applied methodology is the descriptivedeductive method, using normative and bibliographic technique of qualitative nature.
\end{abstract}

KEY-WORDS: Environment; sustainability; pesticides; principles.

\section{INTRODUÇÃO}

A popularização do uso de pesticidas restou impulsionada por seus resultados capazes de obstar a ação danosa de pragas e organismos patógenos, que comumente se

\footnotetext{
* Pós-graduada em Direito Processual Civil (lato sensu) pela Universidade Federal do Amazonas. Mestranda em Direito Ambiental pela Universidade do Estado do Amazonas. Orcid: http://orcid.org/0000-0003-2640-134X. CV: http://lattes.cnpq.br/0199478812255957. E-mail: mgrps.uea@gmail.com.
} 
proliferam na fauna e flora, permitindo melhor proveito no volume das colheitas e conseguinte redução de perdas ao longo da atividade campesina.

O emprego maximizado de agroquímicos no processo produtivo, em contrapartida, tornou perceptível o potencial dos seus efeitos danosos ao meio ambiente e à saúde humana, passando a recomendar prudência no seu manejo para estrito alinhamento ao princípio do desenvolvimento sustentável.

O propósito de sustentabilidade no uso dos recursos naturais, difundido desde a Política Nacional do Meio Ambiente, foi igualmente reverberado no Relatório de Brundtland, na Conferência sobre Meio Ambiente e Desenvolvimento, na Convenção sobre Diversidade Biológica, no Pacto Internacional dos Direitos Econômicos, Sociais e Culturais e no Protocolo de San Salvador.

Partindo-se da premissa de que o direito fundamental ao meio ambiente equilibrado guarda relação com à sadia qualidade de vida, o presente trabalho se propõe a analisar a iniciativa normativa de facilitar o uso de biocidas, dada a perspectiva de flexibilização da matéria através de projeto de lei, entabulado com o escopo de simplificar a expansão do seu emprego e cuja tramitação, em regime de prioridade, aguarda a votação em plenário da Câmara.

A importância do tema emerge das evidências científicas que recomendam cautela no emprego das substâncias em questão ou mesmo a sua substituição por modos de cultura orgânica, diante das ocorrências de intoxicação humana, de liberação de resíduos no ar, água e solo, de degradação dos recursos naturais, de perda de fertilidade no campo, de extermínio de animais silvestres e insetos, entre outros efeitos colaterais associados.

Merece espaço, do mesmo modo, a discussão do tema à vista das disposições constitucionais e internacionais que preconizam tanto a adoção de práticas sustentáveis, como a evolução contínua dos mecanismos de proteção ambiental, com o propósito de garantir a vida humana e os recursos naturais em si para as presentes e futuras gerações, também.

O objetivo geral é analisar o direito fundamental à sadia qualidade de vida e ao meio ambiente equilibrado, constitucionalmente assegurado pela Carta de Outubro, fazendo-o à luz dos princípios da vedação do retrocesso ambiental e do desenvolvimento sustentável, dado o teor da proposição em tramitação no Poder Legislativo de abrandamento das regras sobre agrotóxicos (Projeto de lei nº6.299/2002). 


\section{A PROPOSTA DE FLEXIBILIZAÇÃO DA LEGISLAÇÃO SOBRE AGROTÓXICOS (PROJETO DE LEI №6.299/2002): ANÁLISE À LUZ DO DIREITO FUNDAMENTAL À SADIA CONDIÇÃO DE VIDA E AO \\ MEIO AMBIENTE EQUILIBRADO}

Os objetivos específicos são: delinear o direito fundamental à sadia qualidade de vida e ao meio ambiente equilibrado; compreender a extensão dos princípios do desenvolvimento sustentável e da vedação do retrocesso em matéria ambiental; e avaliar o teor da proposta de flexibilização normativa sobre agrotóxicos (Projeto de Lei nº6.299/2002), em vista da legislação atual, das evidências científicas e dos princípios enumerados precedentemente.

Como método de pesquisa, utilizou-se aquele descritivo-dedutivo, com técnica normativa e bibliográfica de cunho qualitativo, objetivando-se analisar a repercussão do abrandamento normativo proposto, em conformidade com o direito fundamental à sadia qualidade de vida e ao meio ambiente equilibrado.

\section{O DIREITO FUNDAMENTAL À SADIA QUALIDADE DE VIDA E AO MEIO AMBIENTE EQUILIBRADO: COROLÁRIOS DO ESTADO SOCIOAMBIENTAL E DEMOCRÁTICO DE DIREITO}

Indissociáveis do Estado Democrático de Direito, os princípios fundamentais compõem o seu alicerce e encontram enumeração na Lei Maior, cujo elenco exemplificativo comporta direitos elementares, não sujeitos à prescrição e alienação, dentre os quais, aquele da sadia qualidade de vida e ao meio ambiente equilibrado.

O direito fundamental à vida guarda estreita pertinência com a noção de meio ambiente adequado, dado ser imprescindível à própria sobrevivência humana, neste planeta, que os elementos da natureza como a água, o ar e o solo se apresentem em condições favoráveis ao pleno desenvolvimento dos ciclos próprios da vida humana, da fauna, da flora e demais seres vivos.

De fato, como sintetiza Beck, a humanidade não acompanha com indiferença o que se opera em prejuízo do meio ambiente:

\footnotetext{
“Quando árvores são derrubadas e espécies animais extintas, as próprias pessoas se sentem de certa forma afetadas, 'feridas'. As ameaças à vida no desenvolvimento civilizatório revolvem comunhões de experiência da vida orgânica, que vinculam as necessidades vitais do ser humano às das plantas e animais.” (BECK, 2019, p.91).
}

Referida ponderação tanto guarda ressonância no espírito humano que paralelamente ao crescente estímulo às atividades econômicas transnacionais, conflagrou-se um movimento global - derivado da reflexão sobre os danos perpetrados pela ação humana ao meio ambiente e a todos os seres habitantes do globo terrestre - que culminou na Conferência Mundial sobre 
o Meio Ambiente Humano, promovida pela Organização das Nações Unidas - ONU, no ano de 1972, em Estocolmo.

Classificada como marco para enfrentamento da degradação ambiental desencadeada pós-revolução industrial, a Conferência espelhou um consenso internacional acerca da essencialidade do meio ambiente humano para o bem-estar e fruição dos direitos fundamentais em si, neste rol incluído o direito à vida mesma (ONU, 1972).

Em momento seguinte, no Relatório de Brundtland, a Comissão Mundial sobre o Meio Ambiente e Desenvolvimento estabeleceu que o atendimento das necessidades do momento presente, sem comprometimento da capacidade de as gerações futuras suprirem as suas próprias, constituiria a prática do desenvolvimento sustentável, a ser adotada pelas Nações Unidas, governos e instituições, organizações e empresas privadas (ONU, 1987).

Difundiu-se internacionalmente, a partir de então, a percepção da finitude dos recursos naturais e da necessidade de estabelecimento de parâmetros para permitir o desenvolvimento econômico, sem descuidar do viés de sustentabilidade dos meios empregados, com vistas a permitir o uso racional dos recursos naturais. Em outros termos, passou-se a estimular, daquele tempo em diante, a congruência no aproveitamento dos bens ambientais, atendendo-se as necessidades do presente, sem exauri-los.

No plano interno, em alinhamento com os pressupostos do Estado Socioambiental e Democrático de Direito, a Carta Política de 1988 incluiu dentre os princípios gerais da atividade econômica aquele de defesa do meio ambiente, acautelando-se a diferenciação de tratamento quando os produtos, serviços, meios de produção e prestação lhe causem impacto; e também o princípio da função social da propriedade, que fomenta o aproveitamento dos recursos naturais disponíveis de forma racional e adequada, como instrumento para salvaguardar o ecossistema como um todo (BRASIL, 1988).

Ademais, por intermédio da Convenção sobre Diversidade Biológica, atribuiu-se aos Estados a responsabilidade de conservá-la e de utilizar os recursos naturais com sustentabilidade, preservando os ecossistemas in situ e os habitats naturais, e promovendo a repartição justa e equitativa dos benefícios derivados da utilização dos recursos genéticos (BRASIL, 1998).

Com efeito, a proteção ambiental, abrangendo a preservação da natureza em todos os seus aspectos, tem por finalidade tutelar o meio ambiente em decorrência do direito à salutar 


\section{A PROPOSTA DE FLEXIBILIZAÇÃO DA LEGISLAÇÃO SOBRE AGROTÓXICOS (PROJETO DE LEI №6.299/2002): ANÁLISE À LUZ DO DIREITO FUNDAMENTAL À SADIA CONDIÇÃO DE VIDA E AO \\ MEIO AMBIENTE EQUILIBRADO}

qualidade de vida, compreendido em todos os seus desdobramentos, enquanto direito fundamental da pessoa humana (MAZZUOLI, 2018).

E conforme pontua Alexy (2015), o direito humano ao meio ambiente sadio incorpora um feixe de outros direitos, como aquele de o Estado proteger o titular desse direito fundamental contra intervenções de terceiros que sejam lesivas ao meio ambiente (direito à proteção), de se abster de determinadas intervenções no mesmo (direito de defesa), de incluílo em procedimentos de relevo (direito a procedimentos) e adotar medidas fáticas benéficas ao meio ambiente em si (direito à prestação fática).

A compreensão de meio ambiente sadio como um direito fundamental deriva, em suma, do fato de que não é possível, no momento presente, conceber a continuidade da vida humana, sem se assegurar condições de sobrevivência adequada no planeta Terra: o que remete à discussão de parâmetros de desenvolvimento sustentável, sem redundar em retrocesso ambiental.

\section{OS PRINCÍPIOS DO DESENVOLVIMENTO SUSTENTÁVEL E DA VEDAÇÃO DO RETROCESSO AMBIENTAL: A IMPORTÂNCIA DA GESTÃO ADEQUADA DOS RECURSOS NATURAIS}

A revolução industrial iniciada no século XVIII, associada ao crescimento populacional, propiciou mudanças sensíveis no ecossistema, como o exaurimento de recursos naturais, extermínio de espécies, poluição do ar, contaminação de águas e do solo, por exemplo.

A globalização dos danos ambientais se tornou perceptível, espraiando seus efeitos, inclusive, adiante das divisas terrestres fixadas geograficamente entre as Nações, dado que, em menor ou maior grau, os malefícios causados à natureza dentro de um território podem repercutir para além fronteira de outro ou, mesmo, no mundo como um todo.

No Brasil, o estímulo à fruição racional dos recursos naturais pela coletividade, do modo menos gravoso, como exigência de conformação do desenvolvimento econômico e social à preservação do meio ambiente, remonta à edição da Lei nº 6.938 (BRASIL, 1981).

A referida norma instituiu a Política Nacional do Meio Ambiente - PNMA com escopo de preservar e recuperar a qualidade ambiental propícia à vida, sem descuidar de permitir as condições ao desenvolvimento socioeconômico, aos interesses da segurança nacional e à proteção da dignidade da vida humana (BRASIL, 1981). 
No plano regionalizado, o Pacto Internacional dos Direitos Econômicos, Sociais e Culturais - PIDESC lançou em seu texto não apenas a obrigação estatal de assegurar um nível de vida adequado e melhoria contínua das condições de vida humana; mas assim também o encargo de incrementar todos os aspectos do meio ambiente (BRASIL, 1992).

Posteriormente, o Protocolo de San Salvador encerrou a máxima de que "toda pessoa tem direito a viver em meio ambiente sadio e a dispor dos serviços públicos básicos", imputando aos Estados-Partes o encargo de diligenciar pela "proteção, preservação e melhoramento do meio ambiente" (BRASIL, 1999b, art.11, itens 1 e 2).

Associando-se os instrumentos acima descritos, pode-se depreender o desenvolvimento sustentável como "aquele que não sacrifica seu próprio cenário, aquele que não compromete suas próprias condições de durabilidade" (REZEK, 2000, p.237). Com suporte no referido princípio, portanto, conjuga-se o desenvolvimento socioeconômico e a salvaguarda do meio ambiente como instrumento para assegurar a sadia qualidade de vida, compatibilizando o atendimento das necessidades sociais e econômicas do ser humano, no momento corrente, sem comprometer a preservação do meio ambiente em favor da posteridade.

De mais a mais, por força do princípio da boa-fé, o Estado deve cumprir as obrigações que voluntariamente ratificou: esta incumbência deriva do fato de que após a aprovação de tratados de direitos humanos, os Estados se sujeitam a uma ordem jurídica que visa alcançar o bem comum, não em relação a outros Estados, mas quanto a todos os indivíduos sob sua jurisdição (CoIDH, 1982).

Diante dessa ordem de ideias, tem-se que ao ratificar o Protocolo de San Salvador à Convenção Americana de Direitos Humanos (CoIDH, 2017), o Brasil assumiu o compromisso de eficazmente diligenciar pela proteção, preservação e melhoramento do meio ambiente, o que revolve a qualidade e suficiência das fontes hídricas, a propriedade do solo e do ar, a biodiversidade, os recursos energéticos, a situação dos recursos florestais, e, também, a produção de resíduos poluentes e manipulação destes.

Do mesmo modo, quando ratificou a Convenção sobre Procedimento de Consentimento Prévio Informado para o comércio internacional de certas substâncias químicas e agrotóxicos perigosos, conhecida como Convenção de Basileia (BRASIL, 2005), o País assumiu o encargo de contribuir para o uso ambientalmente correto desses produtos, inclusive por intermédio da adoção de providências para assegurar, dentro de suas 


\section{A PROPOSTA DE FLEXIBILIZAÇÃO DA LEGISLAÇÃO SOBRE AGROTÓXICOS (PROJETO DE LEI №6.299/2002): ANÁLISE À LUZ DO DIREITO FUNDAMENTAL À SADIA CONDIÇÃO DE VIDA E AO \\ MEIO AMBIENTE EQUILIBRADO}

possibilidades, o emprego de alternativas mais seguras para a saúde humana ou o meio ambiente.

Exatamente porque o direito fundamental ao meio ambiente ecologicamente equilibrado caminha essencialmente ao lado de outros direitos difusos, como à sadia qualidade de vida (FORTES, 2019), preconiza o princípio do não retrocesso ou da proibição do retrocesso que não se desconstituam as conquistas ambientais já obtidas, retro marchando a status quo anterior menos favorável (SIRVINSKAS, 2014); dado que a higidez do meio ambiente é necessária à sobrevivência de todas as formas de vida no mundo, inclusive do homem.

A própria Constituição erige uma obrigação de conservação do meio ambiente entre as gerações, encarregando a atual de transmiti-lo às seguintes melhor protegido e conservado. Em outras palavras, as "gerações presentes não têm o direito de entregar às gerações futuras um meio ambiente pior do que receberam das gerações passadas." (MACHADO, 2018).

Possível afirmar, então, que a proibição ao retrocesso em matéria ambiental alcança, inclusive, a função legislativa do Estado, impedindo-lhe de desnaturar as condições normativas em vigor e lhe atribuindo o encargo de aprimorar as normas já existentes, para permitir um melhoramento contínuo das condições para fruição de uma vida digna e saudável (SARLET; FENSTERSEIFER, 2017).

Assim, tanto a persistência no meio ambiente dos pesticidas utilizados no processo produtivo, quanto seu potencial de contaminação de seres vivos encorajam a discussão a respeito da proposta normativa que desidrata o rigor que a matéria recomenda.

\section{A PROPOSTA DE FLEXIBILIZAÇÃO DO EMPREGO DE AGROTÓXICOS: ANÁLISE DA CONGRUÊNCIA NORMATIVA AOS CÂNONES DA PRESERVAÇÃO DA NATUREZA E DA PROTEÇÃO DA VIDA HUMANA}

A mesma Carta Política que assegura o livre exercício de qualquer atividade econômica lícita, igualmente condiciona a iniciativa à observância dos princípios de proteção ao meio ambiente, inclusive mediante previsão expressa de tratamento diferenciado do impacto ecossistêmico dos produtos, serviços e de seus processos de elaboração e de prestação (BRASIL, 1988).

Atribui ao Poder Público, ademais, o controle da produção, comercialização e emprego de técnicas, métodos e substâncias que acarretem risco para o meio ambiente, a 
qualidade de vida e a própria existência em si; como instrumento para conferir eficácia ao direito fundamental ao meio ambiente equilibrado e à sadia qualidade de vida (BRASIL, 1988).

Antes de avançar no tema de biocidas, dada a falta de sintonia de opiniões científicas sobre o assunto, convém citar a ressalva de Beck, quando discorre acerca do processamento de riscos da modernização, no sentido de que 'também 'conhecimentos' e 'explicações' científicas e 'propostas de solução' práticas se contradizem diametralmente com o correr do tempo, conforme o lugar, de acordo com distintas escolas de pensamento, culturas etc." (2019, p.240).

Feita a ressalva, conquanto a indústria de agrotóxicos tenha surgido após a Primeira Guerra Mundial, sua difusão no Brasil se realizou em momento posterior, entre os idos de 1945 a 1985, acompanhando um período de modernização da agricultura nacional (TERRA; PELAEZ, 2009).

Os biocidas integravam espécie de pacote tecnológico para modernização agrícola, conhecido como revolução verde, que englobava "fertilizantes sintéticos, calcário, tratores, sementes certificadas e demais implementos agrícolas." (CARVALHO; NODARI E.; NODARI R., 2017).

Nota-se que, no ordenamento pátrio, a normatização infraconstitucional sobre agrotóxicos reconhece sua aptidão para alterar a composição da flora ou da fauna, mas legitima seu uso através de uma associação positiva da substância com a noção de proteção e preservação da ação danosa de outros seres vivos (BRASIL, 2002).

Não se olvida que o emprego de pesticidas contribuiu para o incremento dos níveis de produtividade e que os resultados positivos favoreceram a intensificação do uso inicial de organoclorados - DDT, seguido dos organofosforados e dos carbamatos (SILVA, 2000). No entanto, também, desencadeou efeitos negativos à qualidade de vida e ao meio ambiente.

Veja-se que o uso de biocidas na atividade agrícola contribuiu para o desenvolvimento de resistência aos ativos por algumas espécies, a eclosão de pragas secundárias, a intoxicação aguda de trabalhadores agrícolas, a liberação de resíduos no ambiente e contaminação de alimentos, a degradação de recursos naturais, a modificação na vegetação, o extermínio de espécies animais, insetos e fungos, além da poluição do solo, água e $\operatorname{ar}$ (SILVA, 2000). 


\section{A PROPOSTA DE FLEXIBILIZAÇÃO DA LEGISLAÇÃO SOBRE AGROTÓXICOS (PROJETO DE LEI №6.299/2002): ANÁLISE À LUZ DO DIREITO FUNDAMENTAL À SADIA CONDIÇÃO DE VIDA E AO \\ MEIO AMBIENTE EQUILIBRADO}

Natural, por conseguinte, que em um panorama onde o setor primário da economia é mercado consumidor de pesticidas, o apelo ao seu emprego para a propulsão dos resultados do agronegócio ressoe na mesma intensidade que as vozes contrárias ao uso dos pesticidas na atividade.

Dentre os 50 produtos químicos mais aplicados na atividade de agricultura no Brasil, 22 não são permitidos pelos Estados Unidos da América - EUA e pela União Europeia - EU; no rol dos quais haveria agentes que causam "cegueira, malformação fetal, câncer (em especial os de tireoide e mama), puberdade precoce, problemas respiratórios e disfunções renais" (SIRVINSKAS, 2014, p.503), além de danos à fauna e flora.

$\mathrm{Na}$ atualidade, a Agência Nacional de Vigilância Sanitária, utilizando os parâmetros de classificação toxicológica de agrotóxicos com amparo nos padrões do Sistema Globalmente Harmonizado de Classificação e Rotulagem de Produtos Químicos (Globally Harmonized System of Classification and Labelling of Chemicals - GHS), operou uma reclassificação toxicológica, por meio da Resolução-RE n².080 (BRASIL, 2019).

Na ocasião, houve a avaliação de 1.942 itens, universo no qual promoveu-se a reclassificação de 1.924 deles, distribuídos nas categorias de extremamente tóxico (faixa vermelha: 43), altamente tóxico (faixa vermelha: 79), moderadamente tóxico (faixa amarela: 136), pouco tóxico (faixa azul: 599), improvável de causar dano agudo (faixa azul: 899), não classificado (faixa verde:168), não informado (16) e processo matriz não localizado (2). (ANVISA, 2019a).

Consoante já ponderado no capítulo precedente, do legislador ordinário aspira-se a observância ao princípio da proibição do retrocesso ambiental que, em linhas gerais, obsta a redução ou supressão de direitos já incorporados ao patrimônio jurídico protegido.

Diante desse contexto, em atenção aos princípios norteadores da proteção da biodiversidade e de recursos naturais, à luz da Magna Carta e dos instrumentos convencionais no plano internacional, passa-se a analisar a legislação interna atinente aos praguicidas, no tocante ao impacto biológico da flexibilização normativa proposta pelo Projeto de Lei nº.299 (BRASIL, 2002), em tramitação na Câmara dos Deputados ${ }^{1}$.

Observe-se que, nada obstante, o rigor legislativo da norma corrente (BRASIL, 1989):

\footnotetext{
${ }^{1}$ O projeto tem origem no Senado Federal, onde foi processado como PLS nº526/1999 (BRASIL, 1999a).
} 
No Brasil, a cada ano, cerca de 500 mil pessoas são contaminadas por agrotóxicos, segundo o Sistema Único de Saúde (SUS) e as estimativas da Organização Mundial da Saúde (OMS). Os brasileiros estão consumindo alimentos com resíduos de agrotóxicos acima do limite permitido e estão ingerindo substâncias tóxicas não autorizadas (CARNEIRO, 2016, p.7).

De sua parte, o penúltimo relatório de análises de amostras ${ }^{2}$, monitoradas no período de 2013 a 2015, elaborado pelo Programa de Análise de Resíduos de Agrotóxicos em Alimentos - PARA e divulgado pela Agência Nacional de Vigilância Sanitária - ANVISA, destaca haver subnotificação das intoxicações agudas causadas pela ingestão de resíduos de agrotóxicos, através dos alimentos (ANVISA, 2016).

A subnotificação derivaria da similaridade de muitos dos sintomas clínicos da intoxicação aguda por determinados agroquímicos com aqueles oriundos de intoxicação alimentar de caráter microbiológico (ANVISA, 2016); dificultando-se, sobremaneira, o diagnóstico, registro e direcionamento dos pacientes intoxicados ao protocolo adequado (LONDRES, 2011).

Aliás, segundo a OMS, a subnotificação das intoxicações por agrotóxicos sucede na ordem de 1:50, ou seja, para cada caso notificado, existem outros cinquenta que não o foram (CARNEIRO et al, 2015). Circunstância que sinaliza a imprecisão dos dados registrados numa escala não desprezível.

E mesmo em se considerando a rotineira ausência de sintonia dos dados registrados com a realidade fática, 84.206 casos de intoxicação por agrotóxicos no Brasil foram oficialmente reportados, entre os anos de 2007 e 2015; merecendo destaque a contabilização recorde registrada em 2014 no Sistema de Informações de Agravos de Notificação - SINAN, perfazendo 6,26 casos para cada 100 mil habitantes (ANVISA, 2018).

A subnotificação, contudo, não seria exclusividade nacional. Estima a Organização Mundial de Saúde - OMS que, por ano, a população mundial intoxicada por agrotóxicos alcançaria a casa de 5 milhões de habitantes, dentre os quais uma parcela seria acometida de efeitos adversos como distúrbios neurológicos (700 mil casos), outra fração desenvolveria câncer (80 mil) e alguns sucumbiriam (660 mortes/dia). (SOUZA; FOLGADO, 2016).

\footnotetext{
${ }^{2}$ No último relatório de análises de amostras, monitoradas no período de 2017 a 2018 , não houve espaço ao tema de subnotificação das intoxicações agudas, relacionadas aos alimentos integrantes da dieta básica da população (ANVISA, 2019).
} 


\section{A PROPOSTA DE FLEXIBILIZAÇÃO DA LEGISLAÇÃO SOBRE AGROTÓXICOS (PROJETO DE LEI №6.299/2002): ANÁLISE À LUZ DO DIREITO FUNDAMENTAL À SADIA CONDIÇÃO DE VIDA E AO MEIO AMBIENTE EQUILIBRADO}

Destaca-se, aliás, a previsão de um aumento entre 2010 e 2020 de $15 \%$ dos óbitos causados por doenças crônicas não transmissíveis, que tenham os biocidas entre seus agentes causadores (SOUZA; FOLGADO, 2016). Percentual que espelha os efeitos negativos do seu uso para a vida humana.

Quanto aos alimentos, o penúltimo relatório apurado pelo Programa de Análise de Resíduos de Agrotóxicos em Alimentos - PARA analisou de forma inédita o risco agudo para a saúde, que se associa às intoxicações manifestadas no período de vinte e quatro horas após o consumo do alimento contaminado por resíduos de agrotóxicos (ANVISA, 2016).

Na ocasião, 12.051 amostras de 25 alimentos de origem vegetal, que compõem a dieta da população brasileira, foram testadas para até 232 agrotóxicos diferentes. Neste conjunto de amostras, considerou-se o percentual de 80,3\% como satisfatórias. Deste rol, 38,3\% apresentavam resíduo de agrotóxicos, mas dentro do limite máximo de resíduos LMR convencionado (ANVISA, 2016).

No universo das amostras classificadas como insatisfatórias (19,7\%), $3 \%$ apresentaram concentração de resíduos acima do LMR e 18,3\%, resíduos de agrotóxicos não autorizados para a cultura (ANVISA, 2016). Contabilizando tais percentuais, é certo deduzir que 58\% das amostras submetidas à análise laboratorial estavam maculadas por vestígios de agroquímicos.

No último relatório, divulgado em 2019, houve monitoramento dos alimentos de origem vegetal componentes da dieta alimentar do brasileiro, no ciclo 2017 a 2018 . E de modo pioneiro, analisou-se a "exposição crônica a partir de dados de monitoramento de resíduos de agrotóxicos em alimentos" (ANVISA, 2019b, p.111).

\footnotetext{
Em relação à avaliação da exposição crônica, conduzida a partir de dados de monitoramento do período de 2013 a 2018, não se identificou extrapolação da Ingestão Diária Aceitável (IDA) para nenhum dos agrotóxicos avaliados. A maior parte dos ingredientes ativos alcançou valores de percentuais da IDA inferiores a $10 \%$. Os alimentos monitorados constituem cerca de $73 \%$ do consumo de alimentos de origem vegetal no Brasil e são, portanto, representativos da dieta alimentar nacional. (ANVISA, 2019b, p.111)
}

A partir do relatório de 2019, nota-se que houve a diminuição do número de amostras, quando se realiza a comparação com o expediente precedente. Foram analisados 4.616 fragmentos de 14 alimentos de origem vegetal para até 270 agrotóxicos, enquanto os 
dados anteriores foram coletados a partir de testes em 12.051 amostras de 25 alimentos, ressalvado que, naquela ocasião, empregou-se um rol menor de substâncias (232).

Ainda mediante comparação dos números de um e outro relatório, tem-se que o percentual de amostras satisfatórias diminuiu de $80,3 \%$ para $77 \%$ e houve majoração das amostras classificadas como insatisfatórias de $19,7 \%$ para $23 \%$.

Do total das amostras analisadas, $3.544(77 \%)$ foram consideradas satisfatórias quanto aos agrotóxicos pesquisados, sendo que em 2.254 (49\%) não foram detectados resíduos e 1.290 (28\%) apresentaram resíduos com concentrações iguais ou inferiores ao LMR. Foram consideradas insatisfatórias 1.072 amostras (23\%). (ANVISA, 2019b, p.111)

A classificação da amostra como insatisfatória dependia da constatação de uma das seguintes irregularidades: a) a concentração acima do $\operatorname{LMR}(5,4 \%)$; b) a presença de ingrediente ativo não permitido para a cultura (20,4\%); e c) resíduo de ingrediente ativo proibido, banido ou não permitido no Brasil (0,9\%). Contabilizando-se as amostras classificadas como insatisfatórias $(23 \%)$ e aquelas com resíduos dentro do LMR (28\%), temse que $51 \%$ dos alimentos auditados apresentavam traços de agrotóxicos.

Ainda do relatório, colhe-se o achado de potencial de risco agudo em 41 amostras, dada a concentração de resíduos de agrotóxicos com aptidão a ocasionar efeitos adversos à saúde, dentre os quais o ingrediente ativo carbofurano, detectado em $91 \%$ dos fragmentos e cujo emprego jaz proibido desde a Resolução da Diretoria Colegiada - RDC n 185 (ANVISA, 2017).

De mais a mais, além do trabalhador que os manipula e do alimento afetado por contaminação em si, a aplicação dos biocidas se propaga pela fauna, flora, solo, ar e água, neste rol incluídos os lençóis freáticos subterrâneos; lançando seus efeitos colaterais para fora dos limites da área de aplicação do químico e, por via de consequência, atingindo não só a população local, mas toda aquela abastecida pela fonte contagiada (GREENPEACE, 2017).

Não custa registrar que o modelo de cultura agrotóxico-dependente fomenta um mercado bilionário, administrado por multinacionais de grande porte que monopolizam a produção de insumos agrícolas, incluindo sementes e biocidas (FRIEDRICH; SOUZA; CARNEIRO, 2018); sendo possível citar algumas das sediadas no Brasil, tais como: Basf, Bayer, Dupont, Monsanto, Syngenta, Dow (CARNEIRO et al, 2015).

Conquanto se incentive o uso de pesticidas como forma de impulsionar os resultados do agronegócio, há estudos demonstrando que os sistemas orgânicos de produção são aptos a 


\section{A PROPOSTA DE FLEXIBILIZAÇÃO DA LEGISLAÇÃO SOBRE AGROTÓXICOS (PROJETO DE LEI №6.299/2002): ANÁLISE À LUZ DO DIREITO FUNDAMENTAL À SADIA CONDIÇÃO DE VIDA E AO MEIO AMBIENTE EQUILIBRADO}

alcançar rendimentos físicos iguais ou superiores aos daqueles que lançam mão de praguicidas (BADGLEY et al, 2007).

Além do mais, não ressoa acorde com a realidade a ideia de que o aumento da produtividade agrícola propiciada por emprego de agroquímicos redundaria no expurgo da fome. Ao reverso, em 2007, The Food and Agriculture Organization - FAO, órgão das Nações Unidas para a Alimentação e a Agricultura, divulgou um relatório em que advertiu acerca do crescimento do uso de agroquímicos, desacompanhado da correspondente produtividade das culturas; destacando que o modelo agrícola contemporâneo produziria o suficiente em alimentos para suprimento global, mesmo assim a fome atingiria quase um bilhão de pessoas (ONU, 2007).

O quadro de insegurança alimentar, pois, não decorreria de uma alegada incapacidade produtiva, mas da dificuldade de acesso a itens de qualidade e aos meios de produção necessários (GREENPEACE, 2017). Não haveria déficit de produção, mas de alcance igualitário pela população mundial.

Como solução, o referido expediente da FAO reforçou o potencial e a necessidade de a agricultura orgânica substituir a convencional, eis que o estímulo ao cultivo orgânico contribuiria para a segurança alimentar global, regional, nacional e doméstica, usando as quatros dimensões de disponibilidade, acesso, estabilidade e utilização (ONU, 2007).

Em compasso dissonante com o padrão normativo progressivamente rigoroso adotado por países desenvolvidos no tratamento conferido ao manejo de biocidas (PERES; MOREIRA; DUBOIS, 2003); o Brasil vem enveredando pela via do abrandamento da legislação acerca do tema.

Após aprovação pela Comissão Especial da Câmara, em sessão do dia 25 de junho de 2018, caminha para apreciação do Plenário daquela Casa Legislativa o Projeto de Lei - PL n6.299 (BRASIL, 2002), concebido originalmente no Senado Federal como PLS n526 (BRASIL, 1999a) e alcunhado de "PL do veneno".

As proposições normativas chanceladas pela Comissão Especial da Câmara no PL nº.299 (BRASIL, 2002), sob o véu de constitucionalidade e legitimidade, possuem disposições que banalizam a exposição a contaminantes e fragilizam o rigor necessário à liberação de agrotóxicos.

Da leitura do PL nº6.299 (BRASIL, 2002) infere-se a substituição do termo "agrotóxico" pelas nomenclaturas "produtos fitossanitários" e "produtos de controle 
ambiental", revigorando-se vocabulário dissociado de ideia de toxicidade, que se assemelha à antiga referência de "defensivos agrícolas", empregada outrora para designar os produtos químicos destinados à atividade rural até a publicação da Constituição de 1988 (PERES; MOREIRA; DUBOIS, 2003).

A partir do confronto do Projeto de lei e das disposições em vigor da Lei $n^{\circ} 7.802$, de 11 de julho de 1989, conhecida como "Lei dos Agrotóxicos", constata-se que algumas disposições desta última não são replicadas pela proposição nova, tal como aquela que veta expressamente o uso de biocidas, seus componentes e afins, para os quais não se disponha de métodos para desativação de seus componentes, de antídoto ou tratamento eficaz (BRASIL, 1989).

O Projeto de Lei, igualmente, não repete a previsão hodierna que bane as substâncias que possuam características teratogênicas, carcinogênicas ou mutagênicas; provoquem distúrbios hormonais, danos ao aparelho reprodutor; ou se revelem mais perigosos para o homem do que os verificados em testes de laboratório com animais (BRASIL, 1989).

Não reproduz, também, a proibição vigente dos biocidas cujas características causem danos ao meio ambiente, consoante resultados, procedimentos e experiências emanadas da comunidade científica, a partir de critérios técnicos atualizados (BRASIL, 1989).

Em nítido abrandamento à regra atual, a liberação de substâncias seria delimitada pelo mero enquadramento do risco como aceitável ou inaceitável, consoante se assimila da redação do art. $3^{\circ}, \S \S 6^{\circ}$ e $8^{\circ}$ do PL nº.299 (BRASIL, 2002).

Permitidos, ademais, pelo Projeto de Lei registros ou autorizações temporárias, na hipótese em que os itens já possuam cadastro para culturas similares em, pelo menos, três países-membros da Organização para Cooperação e Desenvolvimento Econômico - OCDE; ou mesmo o emprego de agrotóxicos sem o devido receituário agronômico (BRASIL, 2002).

Inova, ainda, o referido PL com a figura do registro ou autorização temporária pelo decurso do tempo, para as situações de pendência de manifestação conclusiva pelos órgãos responsáveis pela Agricultura, Meio Ambiente e Saúde, dentro do prazo normativo de 30 dias a um ano, conforme a modalidade de registro ou alteração granjeada (BRASIL, 2002).

Descuida de conferir tramitação diferenciada (BRASIL, 2002), em caso de alerta internacional acerca de riscos de determinada substância, de sorte que ao silenciar o texto sobre tema, propicia a perpetuação de risco à saúde e ao meio ambiente, em desalinho com os preceitos magnos da Carta Maior. 


\section{A PROPOSTA DE FLEXIBILIZAÇÃO DA LEGISLAÇÃO SOBRE AGROTÓXICOS (PROJETO DE LEI №6.299/2002): ANÁLISE À LUZ DO DIREITO FUNDAMENTAL À SADIA CONDIÇÃO DE VIDA E AO \\ MEIO AMBIENTE EQUILIBRADO}

Ao se sobrepor aos ditames constitucionais que asseguram a competência concorrente e supletiva das unidades da federação (BRASIL, 1988), o Projeto de Lei dificulta a adoção de iniciativas legislativas regionais de proteção da saúde e do meio ambiente. Citase, como exemplo, a proibição de registro de agroquímico, cujo princípio ativo tenha sido vetado em seu país de origem, adotada internamente nos Estados de Santa Catarina e Espírito Santo (ESPÍRITO SANTO, 1998; SANTA CATARINA, 1998).

A partir das ponderações supra, é possível concluir que a proposta legislativa em tramitação para substituir a Lei $n^{\circ} 7.802$ (BRASIL, 1989) encerra disposições que tanto afrontam a Convenção de Basileia, dado não contemplar a adoção de alternativas mais seguras para a saúde humana ou o meio ambiente; como também representam retrocesso normativo, apto a vulnerar o direito fundamental à sadia qualidade de vida e ao meio ambiente equilibrado, constitucional e convencionalmente assegurado.

\section{CONSIDERAÇÕES FINAIS}

A percepção da essencialidade do meio ambiente adequado para sobrevivência das espécies animais, vegetais e demais seres vivos coabitantes na Terra, e dos danos derivados da ação humana no ecossistema despertaram a consciência coletiva de que a finitude dos recursos naturais e a persistência de alguns efeitos nocivos das práticas correntes recomendavam uma nova postura.

A partir da Conferência Mundial sobre o Meio Ambiente Humano, promovida pelas Nações Unidas, no ano de 1972, desencadearem-se iniciativas para assegurar o direito à vida, por meio da conjugação do desenvolvimento econômico e da sustentabilidade, mediante o uso racional dos recursos naturais em prestígio às presentes gerações, sem prejuízo das futuras.

No plano internacional, houve amadurecimento da discussão em torno do tema, passando-se a difundir a relevância do cuidado no manejo sustentável dos bens ambientais, reverberada no Relatório de Brundtland, na Conferência sobre Meio Ambiente e Desenvolvimento, na Convenção sobre Diversidade Biológica, no Pacto Internacional dos Direitos Econômicos, Sociais e Culturais e no Protocolo de San Salvador.

No Brasil, desde a instituição da Política Nacional do Meio Ambiente, no início da década de 1980, vem-se estimulando a fruição racional dos recursos naturais pela coletividade, do modo menos gravoso. De sua parte, a Magna Carta ao tempo que assegura o 
livre exercício de qualquer atividade econômica lícita, recomenda o respeito aos princípios de proteção ao meio ambiente, inclusive quanto ao tratamento a ser dispensado aos efeitos para o ecossistema de alguns produtos, serviços e de seus processos de elaboração e de prestação. E por não admitir retrocesso em matéria ambiental, confere à geração atual o encargo de transmitir à futura um Planeta melhor do que por si recebido da geração precedente.

No tocante ao tema da repercussão ecossistêmica dos processos de produção do agronegócio, nota-se que a introdução em escala dos agroquímicos sucedeu a contar dos idos de 1945, dando vazão a um processo conhecido como revolução verde, dado seu potencial para incrementar os níveis de produtividade; nada obstante, os efeitos negativos deles consequentes à qualidade de vida e ao meio ambiente.

No Brasil, onde o setor primário é responsável pelo impulsionamento da economia, o consumo de agrotóxicos possui relevância e franca disseminação, o que se reflete nos dados contabilizados pela Agência Nacional de Vigilância Sanitária, quando da última análise de resíduos de agrotóxicos em alimentos, divulgada em 2019, onde 28\% das amostras apresentavam resíduo de agroquímicos, mas dentro do limite máximo de resíduos - LMR convencionado, e outras $23 \%$ enquadradas como insatisfatórias.

Segundo estudos, o uso de agrotóxicos não seria a única via disponível para alcance de produtividade agrícola, podendo a cultura orgânica substituir a convencional, sem que a mudança impacte negativamente nos resultados das colheitas ou prejudique a segurança alimentar e o ecossistema.

Nesse panorama, o Projeto de Lei - PL nº6.299/2002 - concebido originalmente no Senado Federal (PLS n526/1999) e alcunhado de "PL do veneno" - ao abrandar as regras vigentes de trato com o biocidas, desvia-se dos ditames da Convenção de Basileia e representa retrocesso normativo, malferindo a proteção ao direito fundamental à sadia qualidade de vida e ao meio ambiente equilibrado que deve informar a atuação do Estado, inclusive legislativa.

\section{REFERÊNCIAS}

ALEXY, Robert. Teoria dos direitos fundamentais. Tradução Virgílio Afonso da Silva. São Paulo: Malheiros, 2015.

AGÊNCIA DE VIGILÂNCIA SANITÁRIA - ANVISA. Programa de análise de resíduos de agrotóxicos em alimentos - PARA. Brasília, 2016. 246 p. Disponível em: 


\section{A PROPOSTA DE FLEXIBILIZAÇÃO DA LEGISLAÇÃO SOBRE AGROTÓXICOS (PROJETO DE LEI №6.299/2002): ANÁLISE À LUZ DO DIREITO FUNDAMENTAL À SADIA CONDIÇÃO DE VIDA E AO MEIO AMBIENTE EQUILIBRADO}

$<$ http://portal.anvisa.gov.br/documents/219201/2782895/Relat\%C3\%B3rio+PARA/a6975824 -74d6-4b8e-acc3-bf6fdf03cad0?version=1.0 >. Acesso em: 10 fev. 2020.

Resolução RDC n 185, de 18 de outubro de 2017. Diário Oficial [da] República do Brasil. Brasília, DF, 19 out. 2017. Disponível em: <http://www.in.gov.br/materia//asset_publisher/Kujrw0TZC2Mb/content/id/19362345/do1-2017-10-19-resolucao-n-185-de18-de-outubro-de-2017-19362255 >. Acesso em: 10 fev. 2020.

Relatório nacional de vigilância em saúde de populações expostas a agrotóxicos. Brasília: Ministério da Saúde, 2018. Vol. 1, Tomo 2, 191 p. Disponível em: <http://bvsms.saude.gov.br/bvs/publicacoes/relatorio_nacional_vigilancia_populacoes_expost as_agrotoxicos.pdf $>$. Acesso em: 10 fev. 2020.

. Marco Regulatório: publicada reclassificação toxicológica de agrotóxicos [S.I.] divulgado em 01 ago. 2019. Última modificação: 08 ago. 2019. Disponível em: <http://portal.anvisa.gov.br/noticias?p_p_id=101_INSTANCE_FXrpx9qY7FbU\&p_p_col_id $=$ column-

$2 \& p \_p \_c o l \_p o s=1 \& p \_p \_c o l \_c o u n t=2 \& \_101 \_I N S T A N C E \_F X r p x 9 q Y 7 F b U \_g r o u p I d=21920$ $1 \&$ 101_INSTANCE_FXrpx9qY7FbU_urlTitle=publicada-reclassificacao-toxicologica-deagrotoxicos\&_101_INSTANCE_FXrpx9qY7FbU_struts_action=\%2Fasset_publisher\%2Fview_content\& _101_INSTANCE_FXrpx9qY7FbU_assetEntryId=5578706\&_101_INSTANCE_FXrpx9qY7

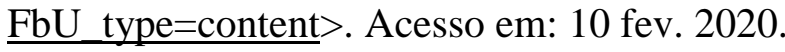

Programa de análise de resíduos de agrotóxicos em alimentos - PARA: Relatório das amostras analisadas no período de 2017-2018 - Primeiro ciclo do plano plurianual 20172020. Brasília: ANS, 10 dez. 2019. 136 p. Disponível em:

$<$ http://portal.anvisa.gov.br/documents/111215/0/Relat\%C3\%B3rio+\%E2\%80\%93+PARA+2 017-2018_Final.pdf/e1d0c988-1e69-4054-9a31-70355109acc9>. Acesso em: 10 fev. 2020.

BECK, Ulrich. Sociedade de risco: rumo a uma outra modernidade. Tradução Sebastião Nascimento. 2. ed. (3ª reimpressão). São Paulo: Editora 34, 2019.

BADGLEY, Catherine et al. Organic agriculture and the global food suply. Renewable Agriculture and Food Systems. Cambridge, UK: Cambrige University Press, 2007. p.86-108. Disponível em: <https://beahrselp.berkeley.edu/wp-content/uploads/2010/06/OrganicAgriculture-and-the-Global-food-Supply.pdf >. Acesso em: 10 fev. 2020. 
BRASIL. Lei nº.938, de 31 de agosto de 1981. Diário Oficial [da] República do Brasil. Brasília, DF, 2 set. 1981. Disponível em:

<http://www.planalto.gov.br/ccivil_03/leis/L6938.htm>. Acesso em: 10 fev. 2020.

. Constituição Federal, de 5 de outubro de 1988. Diário Oficial [da] República do Brasil. Brasília, DF, 5 out. 1988. Disponível em:

$<$ http://www.planalto.gov.br/ccivil_03/constituicao/constituicao.htm> Acesso em: $10 \mathrm{fev}$. 2020 .

Lei $n^{\circ}$ 7.802, de 11 de julho de 1989. Diário Oficial [da] República do Brasil.

Brasília, DF, 12 jul. 1989. Disponível em: <http://www.planalto.gov.br/ccivil_

03/leis/L7802.htm<. Acesso em: 10 fev. 2020.

Decreto n591, de 6 de julho de 1992. Pacto Internacional sobre Direitos

Econômicos, Sociais e Culturais. Diário Oficial [da] República do Brasil. Brasília, DF, 7 jul. 1992. Disponível em: <https://www.planalto.gov.br/ccivil_03/decreto/19901994/d0591.htm>. Acesso em: 10 fev. 2020.

Decreto n².519, de 16 de março de 1998. Convenção sobre Diversidade Biológica. Diário Oficial [da] República do Brasil. Brasília, DF, 17 mar. 1998. Disponível em: <http://www.planalto.gov.br/ccivil_03/decreto/D2519.htm>. Acesso em: 10 fev. 2020.

Congresso. Senado Federal. Projeto de lei do Senado n526, de 31 de agosto de 1999. Disponível em: 〈https://www25.senado.leg.br/web/atividade/materias/-/materia/41703 >. Acesso: 10 de fev. 2020.

Decreto n³.321, de 30 de dezembro de 1999. Protocolo adicional à Convenção Americana sobre Direitos Humanos em Matéria de Direitos Econômicos, Sociais e Culturais. Protocolo de San Salvador. Diário Oficial [da] República do Brasil. Brasília, DF, 31 dez. 1999. Disponível em: 〈http://www.planalto.gov.br/ccivil_03/decreto/D3321.htm>. Acesso em: 10 fev. 2020.

Congresso. Câmara dos deputados. Projeto de lei nº6.299, de 13 de março de 2002.

Disponível em:

<https://www.camara.leg.br/proposicoesWeb/fichadetramitacao?idProposicao=46249>.

Acesso em: 10 de fev. 2020.

Decreto $\mathrm{n}^{\circ} 5.360$, de 31 de janeiro de 2005. Convenção sobre Procedimento de Consentimento Prévio Informado para o Comércio Internacional de Certas Substâncias Químicas e Agrotóxicos Perigoso. Diário Oficial [da] República do Brasil. Brasília, DF, 1 
fev. 2005. Disponível em: 〈https://www.planalto.gov.br/ccivil_03/_Ato20042006/2005/Decreto/D5360.htm>. Acesso em: 10 fev. 2020.

Agência Nacional de Vigilância Sanitária. Resolução-RE n².080, de 31 de julho de 2019. Diário Oficial [da] República do Brasil. Brasília, DF, 1 ago. 2019. Disponível em: <http://www.in.gov.br/web/dou/-/resolucao-re-n-2080-de-31-de-julho-de-2019-208203097>. Acesso em: 10 fev. 2020.

CARNEIRO, Fernando F. et al (Orgs.). Dossiê ABRASCO: um alerta sobre os impactos dos agrotóxicos na saúde, 2015. 624 p. Disponível em:

<http://www.abrasco.org.br/dossieagrotoxicos/wp-

content/uploads/2013/10/DossieAbrasco_2015_web.pdf> Acesso em: 10 fev. 2020.

CARNEIRO, Fernando. Prefácio. In: SOUZA, Murilo M. O. D.; FOLGADO, Cleber A. R. (Orgs.). Agrotóxicos: violações socioambientais e direitos humanos no Brasil. Goiás:

Editora da Universidade do Estado de Goiás, 2016. p.7-11. Disponível em:

$<$ http://contraosagrotoxicos.org/wp-

content/uploads/2018/02/LIVRO_Agrot\%C3\%B3xicos_Violaes-Socioambientais-e-Direitos-

Humanos-no-Brasil.pdf > Acesso em: 10 fev. 2020.

CARVALHO, Miguel M. X. de; NODARI, Eunice S.; NODARI, Rubens O. "Defensivos" ou "agrotóxicos"? História do uso e da percepção dos agrotóxicos no estado de Santa Catarina, Brasil, 1950-2002. História, Ciências, Saúde - Manguinhos, Rio de Janeiro, v. 24, n. 1, p. 75 91. jan. 2017. Disponível em:

$<$ http://www.scielo.br/scielo.php?script=sci_arttext\&pid=S0104-

59702017000100075\&lng=en\&nrm=iso>. Acesso em: 10 fev. 2020.

CORTE INTERAMERICANA DE DIREITOS HUMANOS - CoIDH. Opinião Consultiva $\mathrm{n}^{\circ} 2$, de 24 de setembro de 1982. Disponível em:

<http://www.corteidh.or.cr/docs/opiniones/seriea_02_esp.pdf $>$. Acesso em: 10 fev. 2020.

. Opinião Consultiva $\mathrm{n}^{\circ} 23$, de 15 de novembro de 2017. Série A, n²3. Disponível em: <http://www.corteidh.or.cr/docs/opiniones/seriea_23_esp.pdf $>$. Acesso em: 10 fev. 2020.

FORTES, Vinícius B. Perspectivas críticas do Direito, da Democracia e da Sustentabilidade. Erechim/RS: Deviant, 2019.

ESPÍRITO SANTO. Lei ordinária n5.760, de 1 de dezembro de 1998. Diário oficial [do]

Estado do Espírito Santo. Vitória, ES, 2 dez. 1998. Disponível em:

Rev. de Direito e Sustentabilidade | e-ISSN: 2525-9687 | Evento Virtual | v. 6 | n. 1 | p. 55-75 | 
<http://www3.al.es.gov.br/Arquivo/Documents/legislacao/html/LEI57601998.html >. Acesso em: 10 fev. 2020.

FRIEDRICH, Karen; SOUZA, Murilo M. O. de; CARNEIRO, Fernando F. (Orgs.). Dossiê ABRASCO ABA: contra o PL do veneno e a favor da Política Nacional de Redução de Agrotóxicos, Rio de Janeiro, julho 2018. Disponível em:

$<$ https://www.abrasco.org.br/site/wpcontent/uploads/2018/08/DOSSIE_NOVO_26_JULHO_Final-compressed2.pdf >. Acesso em: 10 fev. 2020. Paginação irregular.

GREENPEACE. Agricultura tóxica: um olhar sobre o modelo agrícola brasileiro, 2017. 83 p. Disponível em: <http://contraosagrotoxicos.org/wp-content/uploads/2017/11/agriculturatoxica.pdf $>$. Acesso em: 10 fev. 2020.

LONDRES, Flávia. Agrotóxicos no Brasil: um guia para ação em defesa da vida, Rio de Janeiro, 2011. 188 p. Disponível em: <http://contraosagrotoxicos.org/wp-

content/uploads/2016/12/Agrotoxicos-no-Brasil-INTERNET.pdf>. Acesso em: 10 fev. 2020.

MACHADO, Paulo A. L. Direito Ambiental Brasileiro. 26. ed. rev. ampl. e atual. São Paulo: Malheiros, 2018.

MAZZUOLI, Valerio de O. Curso de Direito Internacional Público. 11. ed. Rio de Janeiro: Forense, 2018.

ORGANIZAÇÃO DAS NAÇÕES UNIDAS - ONU. Relatório da Conferência das Nações Unidas sobre o Meio Ambiente Humano. A/CONF.48/14/REV.1. Estocolmo, SWE: 1972. Disponível em: <https://www.un.org/ga/search/view_doc. asp?symbol=A/CONF.48/14/REV.1>. Acesso em: 10 fev. 2020.

Resolução no 42-187. Assembleia Geral, 96a Sessão Plenária, 11/12/1987. Disponível em: 〈https://undocs.org/en/A/RES/42/187>. Acesso em: 10 fev. 2020.

Food and Agriculture Organization of The United Nations - FAO. International conference on organic agricultureand food security, Roma, 2007. 11p. Disponível em: <http://www.fao.org/tempref/docrep/fao/meeting/012/j9918e.pdf $>$. Acesso em: 10 fev. 2020.

SANTA CATARINA. Lei ordinária nº11.069, de 29 de dezembro de 1998. Diário oficial [do] Estado de Santa Catarina. Florianópolis, SC, 29 dez. 1998. Disponível em: <http://leis.alesc.sc.gov.br/html/1998/11069_1998_lei.html>. Acesso em: 10 fev. 2020. 
TERRA, Fábio H. B.; PELAEZ, Victor. A história da indústria de agrotóxicos no Brasil: das primeiras fábricas na década de 1940 aos anos 2000. Anais do $\mathbf{4 7}^{\circ}$ Congresso da Sociedade Brasileira de Economia, Administração e Sociologia Rural. Porto Alegre, 2009.

Disponível em: <http://www.sober.org.br/palestra/13/43.pdf>. Acesso em: 10 fev. 2020

PERES, Frederico; MOREIRA, Josino C.; DUBOIS, Gaetan S. Agrotóxicos, saúde e ambiente: uma introdução ao tema. In: PERES, F.; MOREIRA, JC. (Orgs.). É veneno ou é remédio?: agrotóxicos, saúde e ambiente [online]. Rio de Janeiro: Editora Fiocruz, 2003. p. 21-41. Disponível em: <http://books.scielo.org/id/sg3mt/pdf/peres-978857541317303.pdf>. Acesso em: 10 fev. 2020.

REZEK, José F. Direito internacional público: curso elementar. 8 ed. rev. e atual. São Paulo: Saraiva, 2000.

SARLET, Ingo; FENSTERSEIFER, Tiago. Direito constitucional ambiental [livro eletrônico]. 3. ed. São Paulo: Editora Revista dos Tribunais, 2017.

SILVA, José A. da. Direito Ambiental Constitucional. 3. ed. São Paulo: Malheiros, 2000.

SIRVINSKAS, Luís P. Manual de Direito Ambiental. 12. ed. São Paulo: Saraiva, 2014.

SOUZA, Murilo M. O. D.; FOLGADO, Cleber A. R. (Orgs.). Agrotóxicos: violações socioambientais e direitos humanos no Brasil. Goiás: Editora da Universidade do Estado de Goiás, 2016. 296 p. Disponível em: <http://contraosagrotoxicos.org/wpcontent/uploads/2018/02/LIVRO_Agrot\%C3 \%B3xicos_Violaes-Socioambientais-e-Direitos-Humanos-no-Brasil.pdf $>$. Acesso em: $10 \mathrm{fev}$. 2020. 